\title{
Mediterranean Society of Coloproctology 1st Winter Masterclass
}

\author{
X. Delgadillo ${ }^{1}[$
}

Received: 4 December 2019 / Accepted: 5 February 2020 / Published online: 25 February 2020

(c) Springer Nature Switzerland AG 2020

The Mediterranean Society of Coloproctology (MeSoCoP) held its 1 st Winter Masterclass in Minimally Invasive Surgery in Tirana, Albania, on November 23rd 2019. In association with the Albanian Society of Coloproctology (ASCP) and the American Hospital of Tirana, joined by the International Society of University Colorectal Surgeons (ISUCRS).

The most important topics were discussed in the main auditorium of the Plaza Hotel Tirana. The scientific day was divided into three sessions, the first on Laparoscopy Skills in Colon and Rectal Surgery with great speakers including V. Drakoupulos and M. Pramateftakis from Greece, J.N. Mensah from UK, B. Celep from Turkey and A. Beqiri, This last speaker presented the Albanian experience in LAR.

After a coffee break, the second session, on practical and interactive minimally invasive techniques captured the attention of the large audience and predictably led to prolonged debates. The session included robotic indications for TME presented by K. Mavratonis from Greece, local resection in rectal cancer presented by G. Salgado from Spain and the current standards in ERAS protocol for rectal cancer presented by $\mathrm{S}$. Ramuscello and his team from Italy.

The third session, which followed the lunch break, covered minimally invasive upgrades in TAMIS surgery presented by $\mathrm{G}$. Theodoropoulos from Greece, transanal VRA presented by the local organiser and wonderful host L. Shosha, MIS for anismus presented by M. Pescatori and, closing the scientific day. Robotic Mesh Ventral Rectopexy, state of the art, presented by X. Delgadillo from Switzerland, caused a lively debate.

The warmest thanks are due to all chairmen and speakers, and especially to the huge audience, with their questions and remarks and the fantastic exchange of experiences, knowledge and curiosity, that took place at the end of the Masterclass.

Local and international organisers, invited an outstanding international faculty of coloproctologists and experts in

X. Delgadillo

ex.delgadillo@yahoo.com

1 Centre Médico Chirurgical Volta, rue de la Paix 152,

2300 La Chaux de Fonds, Switzerland related disciplines, obtaining a well-balanced combination of education, experience, and knowledge on the alternative treatment modalities and controversial issues with a dynamic and interactive audience.

The Gala Dinner with the international speakers was outstanding, especially because of the traditional Albanian cuisine.

The members of the scientific and organizing committee clearly achieved their aim of encouraging, challenging, disseminating and coordinating scientific research and experimental work and stimulating cooperation on research projects, and development of innovations and improvements in colorectal surgery. Finally, just a reminder about the MeSoCoP XII meeting, to be held in Naples, Italy late in October 2020. The scientific and organizing committee lead by Prof. F Salvaggi, is focusing on new trends and new modalities in Coloproctological Minimally Invasive Surgery. For more information please visit: http://www.mscp-online.org.

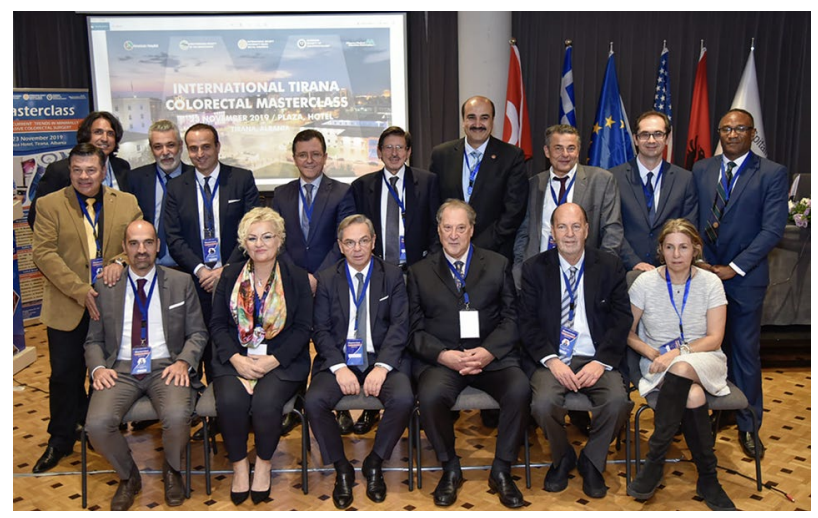

Mediterranean Society of Coloproctology Executive board 2018-2020 and the international faculty invited to the 1st Winter Master Class, Tirana, Albania, November 23rd 2019.

Publisher's Note Springer Nature remains neutral with regard to jurisdictional claims in published maps and institutional affiliations. 